\title{
Influence of zinc oxide in a polar polymer matrix
}

\section{Influencia de óxidos de zinc en una matriz polimérica polar}

GAYTÁN-LARA, Francisco Javier†, CONTRERAS-LÓPEZ, David* and GALINDO-GONZÁLEZ, Rosario

ID $1^{\text {st }}$ Author: Francisco Javier, Gaytán-Lara

ID $1^{\text {st }}$ Coauthor: David, Contreras-López / ORC ID: 0000-0003-1384-4766, CVU CONACYT ID: 38297

ID $2^{\text {nd }}$ Coauthor: Rosario, Galindo-González / ORC ID: 0000-0002-3612-1555, CVU CONACYT ID: 223987

DOI: $10.35429 / J Q S A .2019 .18 .6 .6 .10$

Received January 05, 2019; Accepted April 01, 2019

\begin{abstract}
The creation of films constituted by semiconductor oxides of zinc oxide $(\mathrm{ZnO})$ incorporated into a polar polymer matrix was proposed, looking for such films to be easy to apply, friendly to the environment and compatible with materials. Within the experimental process, the synthesis of styrene copolymers with a polar monomer (methyl methacrylate) was carried out through the suspension and emulsion polymerization processes.
\end{abstract}

Styrene, Suspension Polymerization, ZnO

\begin{abstract}
Resumen
Se propuso la creación de películas constituidas por óxidos semiconductores de $\mathrm{ZnO}$ incorporados a una matriz polimérica polar, buscando que dichas películas sean de fácil aplicabilidad, amigables con el medio ambiente y compatibles con otros materiales y que se mejoren las propiedades conductoras. Dentro del proceso experimental, se llevó a cabo la síntesis de copolímeros de estireno con un monómero polar (metacrilato de metilo) mediante los procesos de polimerización en suspensión y emulsión.
\end{abstract}

Estireno, Polimerización en Suspensión, ZnO

Citation: GAYTÁN-LARA, Francisco Javier, CONTRERAS-LÓPEZ, David and GALINDO-GONZÁLEZ, Rosario. Influence of zinc oxide in a polar polymer matrix. Journal of Quantitative and Statistical Analysis. 2019 6-18: 6-10

\footnotetext{
* Correspondence to Author (email: david.contreras@ugto.mx)

$\dagger$ Researcher contributing as first author.
} 


\section{Introduction}

The articles of common use suffer wear (yellowing) due to UV radiation, an alternative to this problem, consists of the use of coatings, which provide greater protection, without altering the intrinsic properties of the material on which it is applied. For the purposes of this experimental development, we propose the creation of films made of $\mathrm{ZnO}$ incorporated into a polar polymeric matrix, looking for such films to be easy to apply, friendly to the environment and compatible with materials that are applied. Within the experimental process, the synthesis of styrene copolymers with a polar monomer (alkyl acrylate) will be carried out by means of the suspension and emulsion methods, then the synthesis of Zinc oxides will be carried out, which upon incorporation into the polymer matrix is expected to generate a synergy, potentiating the properties of resistance to yellowing of the composite.

Morphological, electrochemical and structural characterization tests will be carried out. The best particle-matrix weight ratio will be found to avoid yellowing of the films and the best matrix particle ratio will be determined when evaluating the dispersion of the oxides in the polymer matrix.

Polymers play an important role in the needs of human consumption today. That is why, for many years, science has worked on the modification of physical and chemical properties of these compounds, in order to produce diverse materials according to the application they require.

In the field of polymer production, we have been working on the search for synthesis processes that can improve the final properties of the polymer or improve the industrial production process. [I].

\section{- $\quad$ Suspension Polymerization}

In it, the polymerization occurs in the liquid phase in the monomer droplets (normally dispersed in water), using a soluble initiator in organic phase (azo- or peroxides) and a stabilization or suspension agent that does not form micelles (used to prevent the coalescence of the drops). The two-phase system is unstable, in the sense that polymerization in suspension is not maintained in the absence of agitation.

\section{- $\quad$ Emulsion polymerization}

The monomer is insoluble in the continuous medium and is suspended to form emulsion drops stabilized using surfactants (surfactants). The initiators used are soluble in water (or in the solvent). In such a way that the polymerization process does not occur in the drops, but in entities formed by the surfactant called micelles, which are fed by the monomer that travels by diffusion through the medium. [II].

Nanotechnology is an emerging interdisciplinary field that has become very popular in many areas over the last decade, including the science of materials, mechanics, electronics, optics, medicine, plastics, textiles, etc.). $\mathrm{ZnO}$ belongs to a group of metal oxides that are characterized by the following properties: photocatalytic capacity, electrical conductivity, UV absorption, photooxidant capacity against chemical products and biological species, antimicrobial and selfsterilization. In addition, $\mathrm{ZnO}$ is generally considered as a safe material for humans and animals, and has been widely used in the formulation of personal care products. [III].

$\mathrm{ZnO}$ ) is a semiconductor that in nanoscale presents an ordered structure, and a great activation energy. The scientific interest in this material arose to recent dates, because it was observed that it is a solid with high mobility of electrons, good conductor of electricity, thermodynamically stable and capable of absorbing visible light.

The production of nanostructured fibers is an area where nanotechnology has had a great impact, since it presents the possibility of manufacturing antimicrobial textiles, which are very useful in the medical field, or the search for materials such as $\mathrm{ZnO}$ that, when irradiated by ultraviolet light, has an antibacterial effect [IV]. Inorganic $\mathrm{ZnO}$ semiconductor exists in two different phases such as zinc blend and hexagonal wurtzite. Among these, hexagonal wurtzite is the commonly observed structure at room temperature. [V].

This project aims to incorporate semiconductor oxide particles in a vinyl-type copolymer to achieve a good dispersion and to evaluate the synergy between the properties of the zinc oxide $(\mathrm{ZnO})$ in combination with the polymers which will generate protective films against deterioration caused by the UV rays. 


\section{Metodology}

Synthesis of $\mathrm{ZnO}$ nanoparticles (wurzite) by the Sol-Gel method.

\section{- Synthesis of polymers}

Prior to any synthesis method, the $\mathrm{ZnO}$ nanoparticles were ground in an agatha mortar and the appropriate amount was weighed according to the desired incorporation either at $1 \%$ or $0.3 \% \mathrm{w} / \mathrm{w}$, placing them in a flask with methanol immersed in a sonicator for $30 \mathrm{~min}$.

\section{- Emulsion polymerization}

Prior to initiating the emulsion synthesis, of $0.68 \%$ Potassium Persulfate solution was prepared. A stirrer, distilled $\mathrm{H}_{2} \mathrm{O}$, sodium Dodecyl sulfate SDS (surfactant) was placed in a beaker and the stirring was started at the appropriate revolutions ( $\mathrm{rpm}$ ) according to the polymer to be obtained as well as the heating in order to reach the desired temperature. Once the reaction temperature was reached, the nanoparticles were added in case of being a polymer with incorporation of nanoparticles. Next, $0.68 \%$ potassium persulfate (used as initiator) and then monomer (s) used were added and then left for the appropriate time for the monomer (s) polymerization.

\section{Suspension polymerization}

A stirrer, the desired continuous medium as well as its dispersing medium was placed in a beaker, stirring and heating was carried out in order to reach the necessary reaction conditions for each polymer.

Once the reaction temperature was reached, the nanoparticles were added in case of being a polymer with incorporation of nanoparticles. Next, $0.68 \%$ potassium persulfate (used as initiator) and then monomer (s) used were added and then left for the appropriate time for the polymerization of each monomer (s). At the end of the reaction, 2 washes were made with tap water and one with distilled water.

The polymer is dried in an oven at $70^{\circ}$ $\mathrm{C}$ for $24 \mathrm{~h}$. The polymers obtained are listed in table 1 .

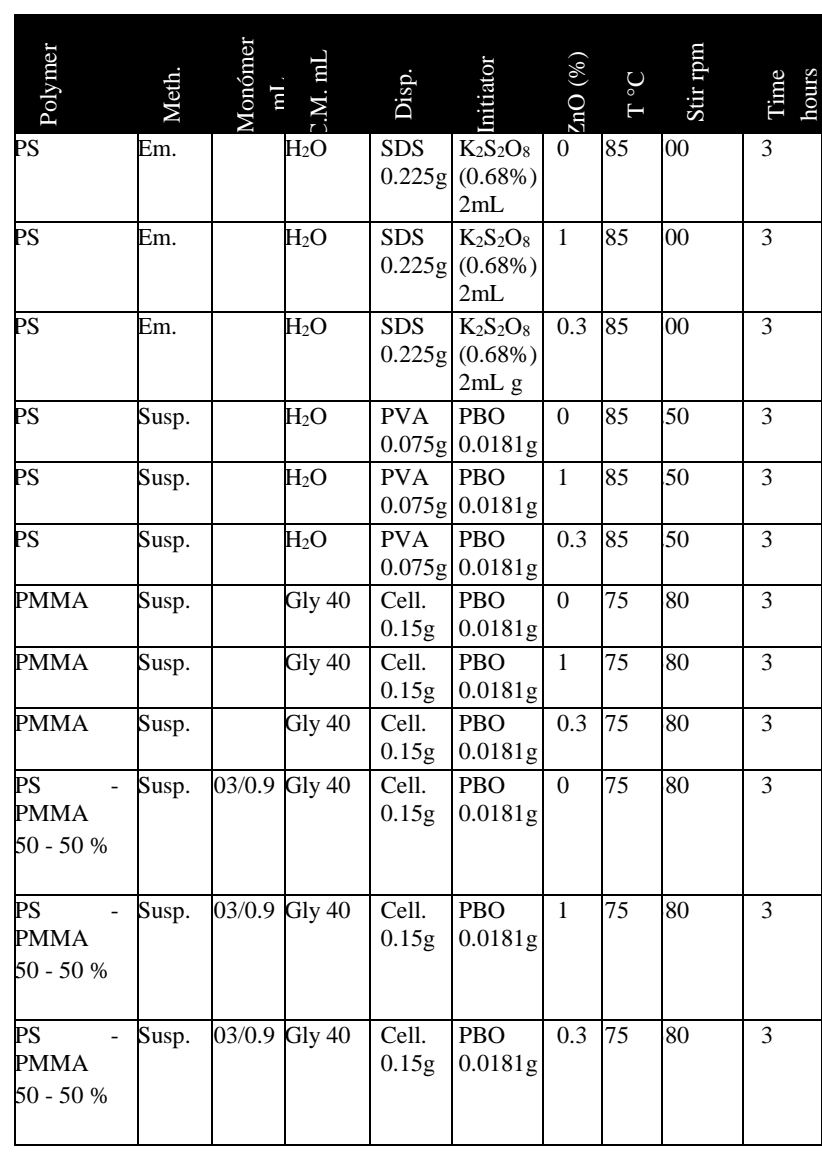

Table 1 PS = Polystyrene, PMMA = Polymethylmethacrylate, SDS = Sodium Dodecyl Sulfate $\mathrm{NaC}_{12} \mathrm{H}_{25} \mathrm{SO}_{4}, \mathrm{PVA}=$ Polyvinyl Alcohol $\left(\mathrm{C}_{2} \mathrm{H}_{4} \mathrm{O}\right) \mathrm{x}, \mathrm{PBO}=$ Benzoyl Peroxide $\mathrm{C}_{14} \mathrm{H}_{10} \mathrm{O}_{4}, \mathrm{~K}_{2} \mathrm{~S}_{2} \mathrm{O}_{8}=$ Potassium Persulfate

\section{Results}

\section{Characterization of $\mathrm{ZnO}$}

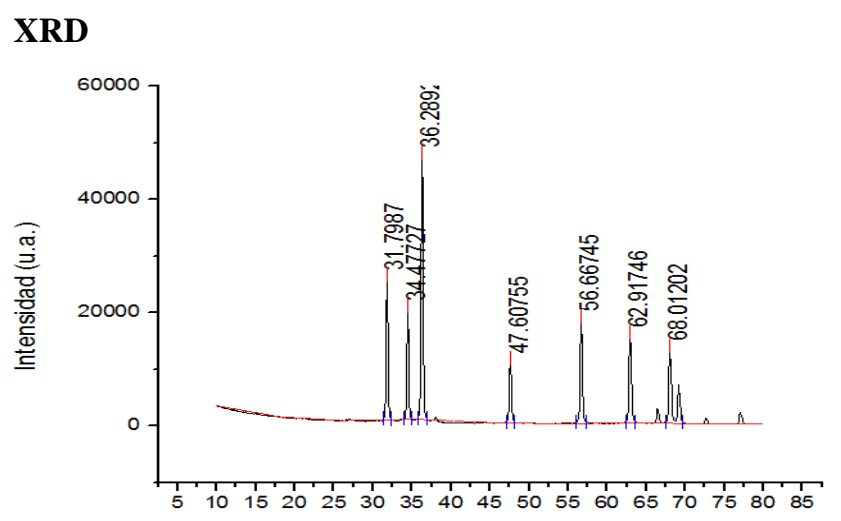

29

\section{ZnO diffractogram synthesized via sol-gel}

With these results the hexagonal wurzite phase is confirmed whose characteristic peaks are located at $32.24^{\circ}\left(31.79^{\circ}\right), 34.42^{\circ}\left(34.47^{\circ}\right)$, $36.25^{\circ}\left(36.28^{\circ}\right), 47.54^{\circ}\left(47.60^{\circ}\right), 56.84^{\circ}$ $\left(56.66^{\circ}\right), 62.86(62.91)$, and $68.76^{\circ}\left(68.01^{\circ}\right)$. 


\section{UV-Vis}

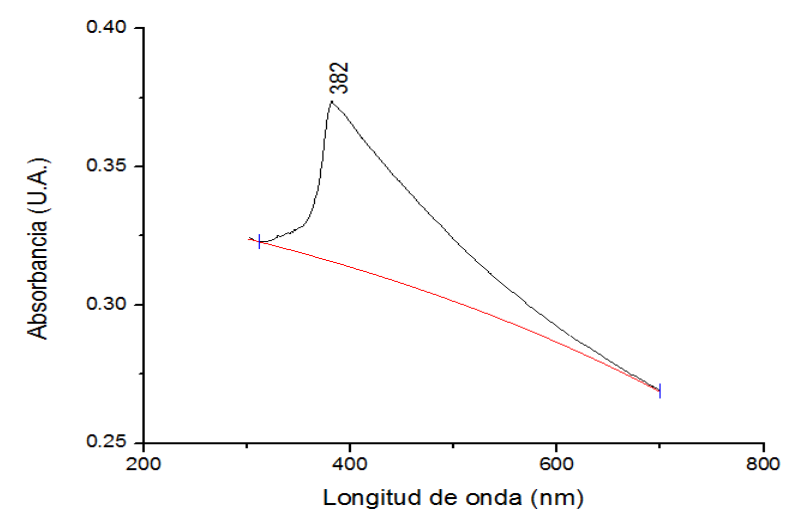

\section{UV-Vis absorption spectrum of $\mathrm{ZnO}$ film}

The presence of $\mathrm{ZnO}$ is confirmed since it is known that UV-Vis has an absorption band at approximately $370 \mathrm{~nm}(382 \mathrm{~nm})$.

\section{Characterization of polymer films}

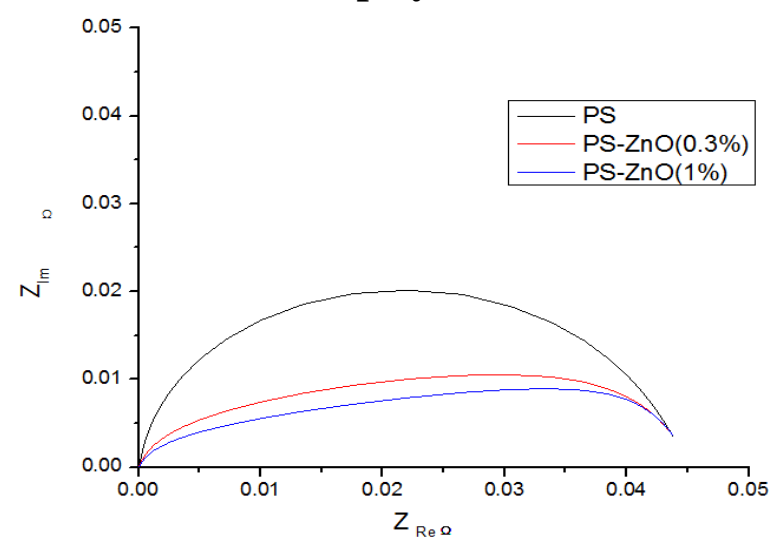

Spectrum of electrical impedance of polystyrene, polystyrene with incorporation of $\mathrm{ZnO}$ at $0.3 \%$ and polystyrene with incorporation of $\mathrm{ZnO}$ at $1 \%$ in $\mathrm{KCl}$

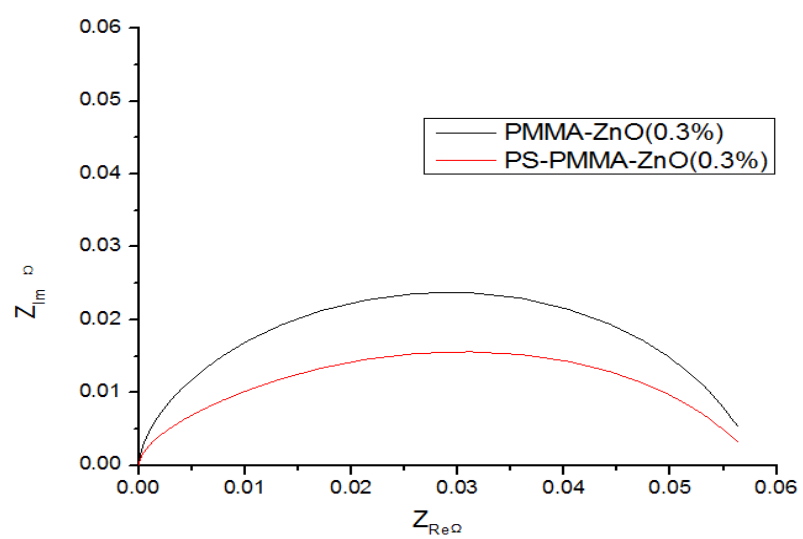

Spectrum of electrical impedance of polymethylmethacrylate with incorporation of $\mathrm{ZnO}$ at $0.3 \%$ and copolymer polystyrenepolymethylmethacrylate with incorporation of $\mathrm{ZnO}$ at $0.3 \%$ in $\mathrm{KCl}$.
Impedance spectroscopy is a technique that indi rectly allowsus to measure the conductive chara cter and the materials. The resistance to the trans fer of load is related to thediameter of the semic ircles that are obtained from thegraph.

We can see that the sample has no $\mathrm{ZnO}$ i $s$ the onethat has the largest diameter, therefore the greatestresistance and with the highest conc entration of $\mathrm{ZnO}$ that is $1 \%$ resistance decreases, indicating that it increases itsconductivity as th ey are reverse measurements.

\section{Conclusions}

The results obtained are conclusive to affirm that the polymerization processes were performed correctly in both emulsion and suspension, the characterization of the PS and PMMA polymers as well as the copolymer gave the expected result, as well as the characterization of the $\mathrm{ZnO}$ nano particles confirms that the sol-gel method was performed correctly.

The experimental methods used gave favorable results, however due to lack of time, more characterization tests are still pending such as SEM microscopy, NMR spectroscopy and FT-IR by diffuse reflectance in order to analyze the dispersion level of the $\mathrm{ZnO}$ particles in the polymer networks synthesized.

As the $\mathrm{ZnO}$ is a material that adsorbs the UV light, we canalso say that the higher conce ntration in the polymer matrixwill favor the prot ection to the solar radiation and theyellowing

\section{References}

I. - Timothy E. Long, James E. McGrath. 2008. "Polymers, Synthesis". Encyclopedia of Physical Science and Technology, 3, 751-774.

II. - Chern, Chorng-Shyan. 2008. "Principles and Applications of Emulsion Polymerization". Wiley VCH.

III.- Perelshtein, I.; Applerot, G.; Perkas, N.; Wehrschetz-Sigl, E.; Hasmann, A.; Guebitz, G. M. \& Gedanken, A. 2008 "Antibacterial Properties of an In Situ Generated and Simultaneously Deposited Nanocrystalline $\mathrm{ZnO}$ on Fabrics". ACS Applied materials and interfaces. 01 December 2008. 
IV. - Shaban, Mohamed; Abdallah, Semsem \& Abdel-Khalek Ahmed. 2016. "Characterization and photocatalytic properties of cotton fibers modified with $\mathrm{ZnO}$ nanoparticles using sol-gel spin coating technique". Beni - suef university journal of basic and applied sciences 5 (2016) $277-283$.

V. - Martin, Morget; Prasad, Neena; MariappanSivalingam, Muthu; Sastikumar, D. \& Karthikeyan, Balasubramanian. 2017. "Optical, phonon properties of $\mathrm{ZnO}-P V A, \mathrm{ZnO}-G O-P V A$ nanocomposite free standing polymer films for UV sensing”. J Mater Sci: Mater Electron. 